\title{
Desenvolvimento dos ovócitos em Harengula clupeola, Urophycis brasiliensis, Eucinostomus argenteus, Isopisthus parvipinnis e Menticirrhus americanus (Teleostei)*
}

\author{
Paulo de Tarso da Cunha CHAVES**
}

Instituto Oceanográfico da Universidade de São Paulo

(Caixa Postal 9075, 01051 São Paulo, SP)

\section{Introdução}

O grau de maturação dos ovários de peixes pode ser avaliado através de vários métodos, tanto qualitativos (analisando-se, p.ex., coloração, vascularização e textura das gônadas), como quantitativos (empregando-se, p.ex., relações numéricas entre peso das gônadas e do corpo ou entre volume das gônadas e dimensōes do corpo). No primeiro grupo, dois métodos são inerentes aos ovócitos em particular: a análise do conteúdo vitelínico e a mensuraçāo de seu tamanho. O conteúdo vitelínico é eficientemente avaliado através de métodos histológicos, os quais, porém, demandam tempo e recursos para sua execução. As mediçōes dos tamanhos ovocitários, por seu lado, requerem o conhecimento prévio dos valores numéricos a que cada nível de desenvolvimento corresponde.
\end{abstract}

(*) Parte da tese de doutorado apresentada ao IOUSP em 18-111988. Trabalho parcialmente financiado pela CIRM.

(**) Ex-bolsista da FAPESP (Proc. 86/0574-8). Endereço atual: Departamento de Biologia Celular, UFPR. Caixa Postal 19031, 81504 Curitiba, PR.
Em vista disso, e considerando-se a importância da identificação das fases ovocitárias para a avaliação dos estádios de maturação gonadal, este trabalho associou, em cinco espécies do litoral de São Paulo, o método histológico ao de medição de ovócitos. As espécies selecionadas para o trabalho foram Harengula clupeola (Clupeidae), Urophycis brasiliensis (Gadidae), Eucinostomus argenteus (Gerreidae), e Isopisthus parvipinnis e Menticirrhus americanus (Sciaenidae), todos de expressiva ocorrência na região, e para os quais a pesquisa bibliográfica nāo acusou a existência de informaçōes prévias sobre fases de maturaçāo ou dimensōes ovocitárias. Pretende-se, assim, (1) reconhecer as fases de desenvolvimento envolvidas no processo de maturação ovocitária, e (2) identificar a faixa de diâmetro a que cada uma dessas fases corresponde nas cinco espécies estudadas.

\section{Material e métodos}

Para estabelecer-se uma correspondência entre as fases de desenvolvimento dos ovócitos e as suas 
dimensões, aplicou-se o modelo apresentado por Greeley Jr. et al. (1987) em Mugil cephalus, confrontando-se:

a) os diâmetros ovocitários de porções de ovários dissociados em solução de Gilson, medidos sob estereomicroscópio; com

b) as fases ovocitárias descritas histologicamente para essas gônadas, de porções mantidas em fixador comum (formol $10 \%$, por duas a 12 semanas).

Os exemplares pertencentes às cinco espécies analisadas - Harengula clupeola $(\mathrm{n}=11)$, Urophycis brasiliensis $(\mathrm{n}=9)$, Eucinostomus argenteus $(\mathrm{n}=7)$, Isopisthus parvipinnis $(\mathrm{n}=9)$ e Menticimhus americanus $(\mathrm{n}=6)$, foram coletados no litoral norte do Estado de São Paulo, entre os anos de 1985e 1987. A fixação das gônadas foi realizada a fresco, geralmente após resfriamento dos peixes em caixas isotérmicas durante algumas horas. Em laboratório efetuou-se a técnica histológica de rotina para coloração HE, adaptada de Behmer et al. (1976), com cortes entre 10 e $16 \mu \mathrm{m}$ de espessura, sobre porções procedentes da regiāo mediana de uma das gônadas de cada par. Para mediçōes de ovócitos sob estereomicroscópio, uma porção de cada gônada analisada histologicamente (e portanto previamente fixada em formol) foi transferida para solução de Gilson modificada (Vazzoler, 1981). Após sua dissociação, mediram-se com ocular micrométrica (1 D.O.M. equivalente a $20 \mu \mathrm{m}$ ) cerca de 450 ovócitos de cada exemplar, um número arbitrário, também adotado por Greeley Jr. et al. (1987) em Mugil cephalus. Estimou-se como representativo de cada unidade o valor de seu diâmetro vertical mediano.

Para cada gônada examinada, estima-se que a moda de maior diâmetro ovocitário corresponda à fase mais madura dos ovócitos identificados histologicamente. Assim, aplicando-se o modelo aplicado por Greeley Jr. et al. (op. cit.), a sobreposição das curvas de diâmetro procedentes de gônadas de sucessivos estádios de maturaçāo, oferece uma estimativa da faixa de tamanho a que corresponde cada fase ovocitária. Por razōes amostrais, as dimensōes de algumas fases intermediárias do processo de vitelogênese não foram obtidas. Todavia, tal fato não deverá comprometer o propósito central do trabalho, pois as fases anteriores e posteriores às ausentes possibilitaram a estimativa destas por interpolaçāo.

\section{Resultados}

\section{Fases do desenvolvimento ovocitário}

Foram identificados histologicamente todos os eventos envolvidos no processo de maturação dos ovócitos. $\mathrm{O}$ padrão é semelhante àquele descrito para outros teleósteos: inicialmente uma intensa basofilia citoplasmática nos ovócitos (Fig. 1a), à qual se segue deposição vitelínica, numa primeira etapa representada por vacúolos sem coloração, de provável origem lipídica (o conteúdo foi extraído na etapa de desidratação); e, após, por grânulos acidófilos, com provável natureza proteínica. Observou-se que o local do citoplasma em que as primeiras vesículas se depositam varia de espécie para espécie: enquanto em Harengula clupeola, Urophycis brasiliensis e Eucinostomus argenteus os vacúolos distribuem-se por sua regiāo cortical (Figs 1a e 1b), em Isopisthus parvipinnis e Menticirnhus americanus eles se concentram na regiāo perinuclear do ovócito (Fig. 1c). Os grânulos acidófilos, por sua vez, ocupam a célula quase integralmente, num mecanismo de substituição aos vacúolos e ao citoplasma basófilo (Fig. 2).

Todo esse processo de deposição de vitelo é acompanhado (1) por um incremento volumétrico do citoplasma, desproporcional àquele sofrido pelo núcleo, (2) por um gradual espessamento da membrana vitelina que cerca os ovócitos, e (3) por um aumento em número das células do envoltório folicular, que no entanto mantêm a sua forma plana. A última etapa do desenvolvimento individual dos folículos consiste na hidrataçāo pré-ovulatória. Manifesta-se o processo por uma crescente homogeneização do citoplasma do ovócito, acompanhada pela migração do núcleo para um dos polos da célula, após a fase de vitelogênese completa (Fig. 3).

Assim, a seqüência de eventos envolvidos na maturação folicular pré-ovulatória dessas espécies pode ser dividida em seis fases:

FASES I e II - os ovócitos ainda não estão em vitelogênese. Folículos da fase I, com núcleo relativamente volumoso e citoplasma escasso, sāo pouco distingüíveis. Os da fase II são aqueles dotados de forte basofilia citoplasmática (Fig. 1a);

FASE III - folículos contendo ovócito em início de vitelogênese. As vesículas vitelínicas não se coram em $\mathrm{HE}$ (Fig. 1).

Fase IV - folículos já com grânulos acidófilos, mas ainda mantendo vesículas da fase anterior (Fig. 2a);

Fase V - folículos cujo ovócito está totalmente preenchido por grânulos acidófilos (Fig. 2b);

Fase VI - folículos com ovócito em hidrataçāo pré-ovulatória (Fig. 3).

\section{Os diâmetros de cada fase}

A observação comparada das fases presentes nas diversas etapas de maturaçāo demonstrou que, nas cinco espécies estudadas, o desenvolvimento dos ovócitos em conjunto obedece ao tipo "sincrônico em mais que dois grupos", de Marza (1938, apud Wallace \& Selman, 1979). $\mathrm{Tal}$ fato antecipadamente sugere dois pontos:

$\left.1^{2}\right)$ que cada indivíduo deve efetuar múltiplas desovas por temporada; e

$2^{2}$ ) que a distribuição individual de frequiência dos diâmetros ovocitários deve possuir mais que duas modas.

De fato, os gráficos apresentados às Figuras $4 d$ e $5 d$ confirmam a tendência polimodal esperada. A grande amplitude de valores observada em torno de cada moda, por sua vez, é explicada pela maneira escolhida para a 


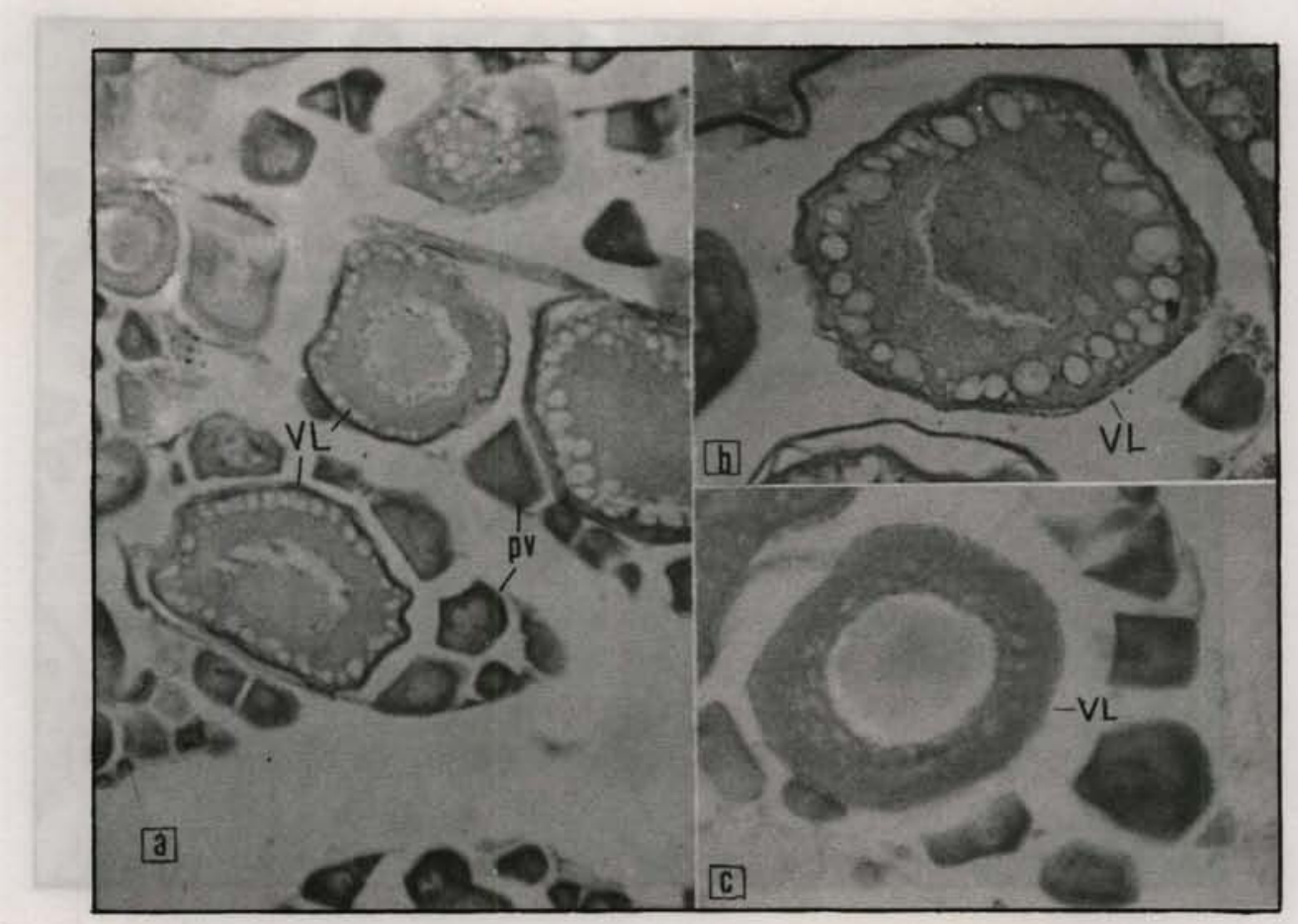

Fig. 1. Cortes histológicos de ovários com folículos em início de vitelogênese (VL). Aumento $10 \times 10$.

a) Urophycis brasiliensis. Vitelogênese a partir do citoplasma cortical do ovócito. pv: folículos basófilos pré-vitelogênicos.

b) Harengula clupeola. Vitelogênesea partir do citoplasma cortical.

c) Menticirrhus americanus. Vitelogênese a partir do citoplasma perinuclear. 


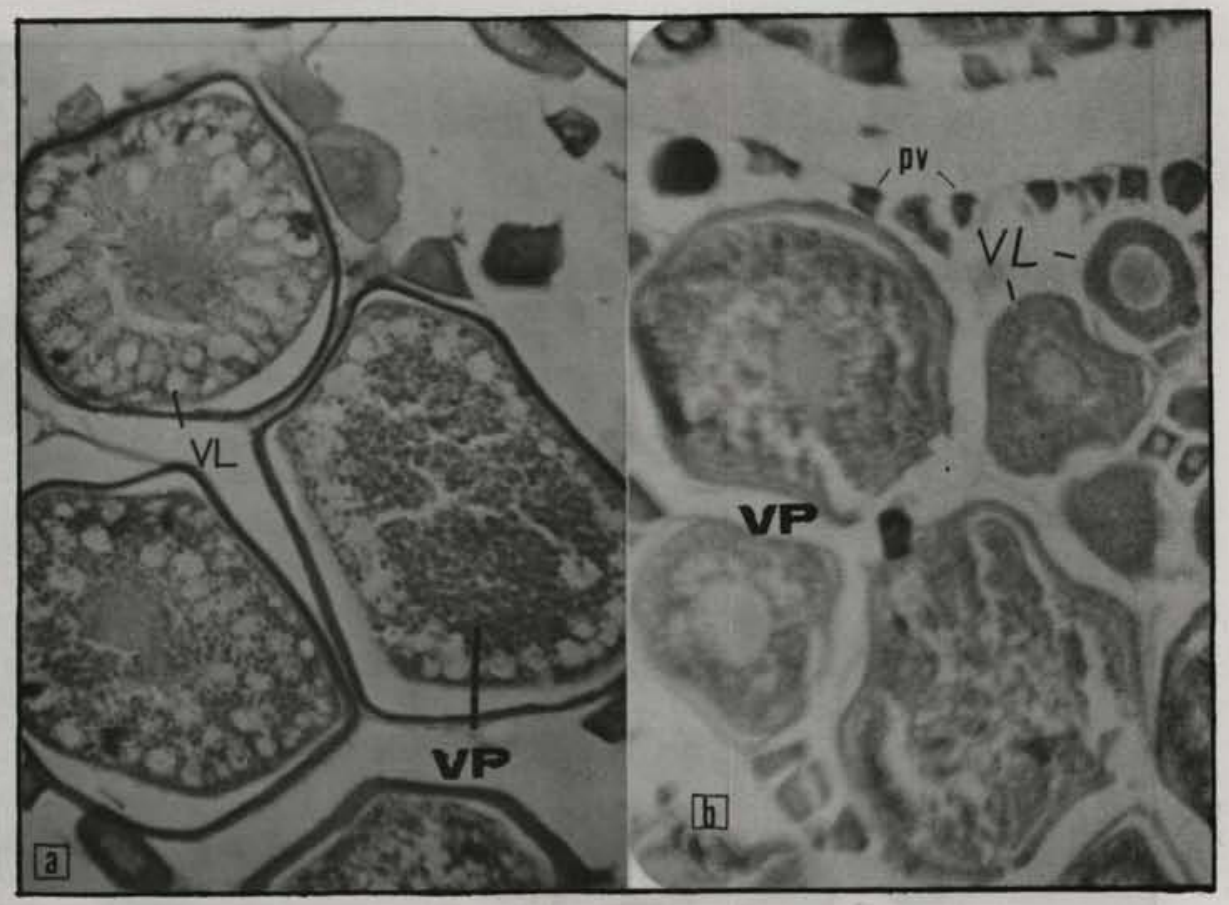

Fig. 2. Folículos em início de vitelogênese (VL) e em vitelogênese acidófila (VP).

a) Urophycis brasiliensis. Folículo VPainda mantendo vacúolos da etapa VL. Aumento $10 \times 10$.

b) Menticirrhus americanus. Folículos VP com vitelogênese acidófila completa. pv: folículos basófilos pré-vitelogênicos. Aumento: $10 \times 4$. 


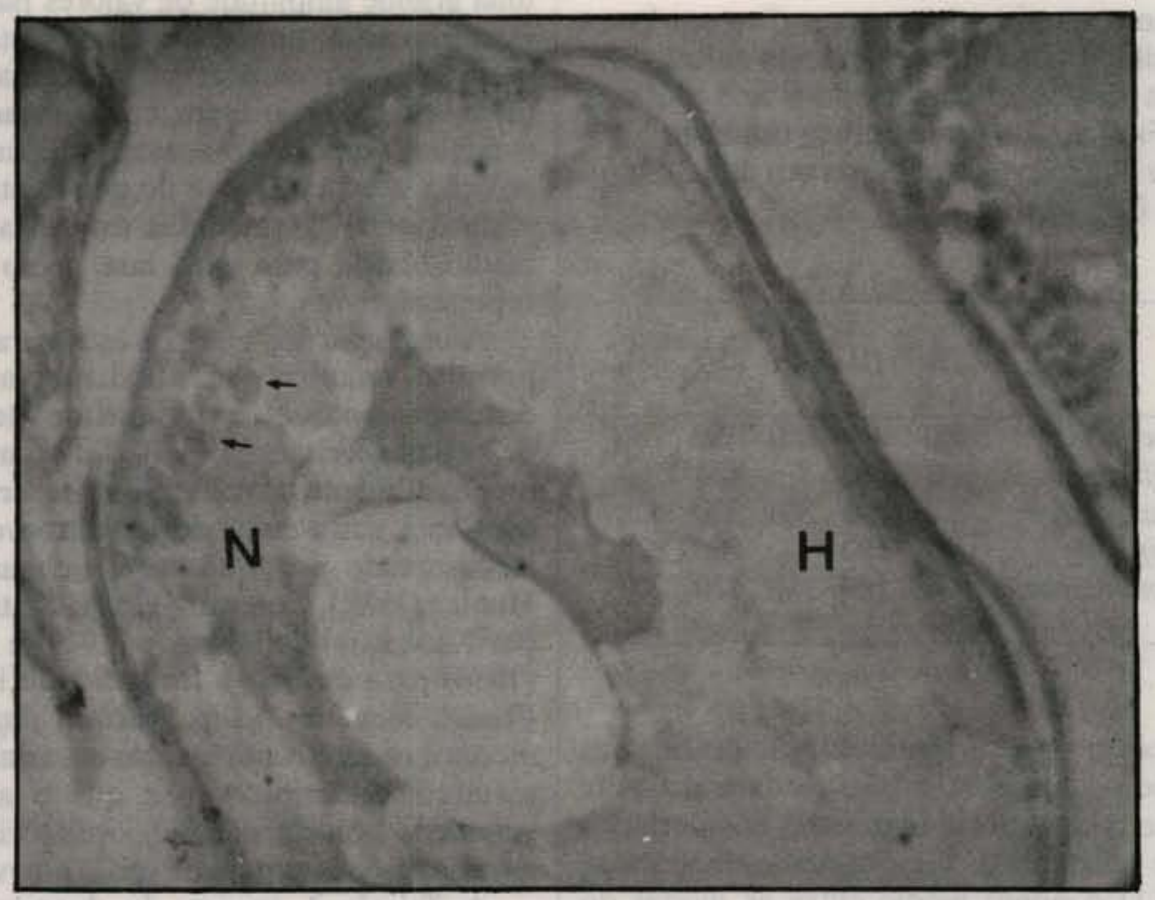

Fig. 3.Menticirrhus americanus. Foliculo hidratado. Núcleo (N) situado num dos polos do ovócito. Citoplasma quase totalmente coalescido $(H)$. Poucos grânulos de vitelo acidófilo (setas). Aumento: 10x10. 
medição dos ovócitos - a dimensão de apenas um diâmetro. Dessa forma, para efeito de comparaçāo, deve-se considerar o diâmetro de cada fase como sendo uma aproximação do valor da moda correspondente. Ou seja: em cada gráfico, a moda mais avançada indica o diâmetro aproximado da fase mais madura registrada histologicamente para aquela gônada. Seguindo esse método, estimou-se a faixa de diâmetro ovocitário ocupada pelas diversas fases de maturação, conforme consta à Tabela 1.

Tabela 1. Diâmetros estimados para as diversas fases ovocitárias nas cinco espécies estudadas. Estes dados correspondem aos gráficos das Figuras 4-8 onde consta também o número de ovócitos medidos em cada exemplar. $\operatorname{Em} \mu \mathrm{m}$

\begin{tabular}{lcccccc}
\hline \multirow{2}{*}{ ESPECIE } & II & III & IV & V & VI \\
& & & & & \\
\hline Harengula clupeola & 100 & - & 260 & 380 & 780 \\
Urophycis brasiliensis & 60 & 220 & - & 420 & 660 \\
Eucinostomus argenteus & - & 180 & 260 & 380 & 620 \\
Isopisthus parvipinnis & 60 & 180 & - & 460 & 820 \\
Menticirrhus americanus & 60 & 140 & - & 420 & 700
\end{tabular}

Tomando-se como base a representação gráfica das Figuras 4 a 8, pôde-se inferir também os diâmetros em que os ovócitos de cada espécie ingressam nos períodos de vitelogênese e hidratação. Para tanto, estimaram-se respectivamente (1) o ponto médio entre as modas do estoque de reserva (ovócitos pré-vitelogênicos) e do primeiro lote vitelogênico, e (2) o ponto médio entre a última moda vitelogênica e a de folículos hidratados. Os valores estimados, assinalados nas próprias figuras, foram respectivamente (em $\mu \mathrm{m}): 140$ e 580 para Harengula clupeola, 100 e 480 para Urophycis brasiliensis, 140 e 480 para Eucinostomus argenteus, 140 e 640 para Isopisthus parvipinnis, e 100 e 540 para Menticirrhus americanus.

\section{Discussão}

Em linhas gerais, o processo de maturação ovocitária nas espécies estudadas segue padrāo semelhante àquele descrito para outros teleósteos, inclusive Clupeiformes, Gadiformes e Perciformes. O tipo estimado de desova confere, p.ex., com o descrito para Menticirrhus americanus a partir de métodos não-histológicos (Alvitres Castillo, 1986), bem como, com uso deste método, para outras espécies de Clupeidae (Isaac-Nahum et al., 1983; Chaves, 1985), Gadidae (Hislop, 1984) e Sciaenidae (Isaac-Nahum, 1981; Haimovici, 1982; Chaves, 1985).

Quanto aos valores numéricos de diâmetro encontrados para as espécies em questão, é necessário que sejam interpretados com cautela. Primeiramente, porque o tamanho dos ovócitos quando maduros pode variar segundo o comprimento dos exemplares analisados
(Davis, 1977) ou a sua procedência geográfica (Bowers \& Holliday, 1961; D’Yakov, 1982). Em segundo lugar, porque esses dados foram obtidos após imersão da gônada em líquido fixador, e não a fresco, como se recomenda em diagnose imediata à coleta. $\mathrm{E}$, por fum, porque o número amostral utilizado neste trabalho foi pequeno: nāo mais que três exemplares para cada fase ovocitária, fato que pode acentuar a primeira das objeçōes referidas.

Para a estimativa do diâmetro, adotou-se apenas o diâmetro vertical mediano de cada ovócito. Isso implicou uma grande amplitude de valores para células de mesma fase, pois nem sempre a medida vertical correspondia ao maior, ou ao menor, ou à média entre esses dois diâmetros. Mesmo assim, como as mediçōes se davam em ovócitos tomados ao acaso, independentemente de sua posição, a expectativa é de que exista uma compensação natural entre as medidas extremas, tornando o ponto médio obtido para cada fase como o seu melhor valor representativo.

A inspeção dos gráficos às Figuras 4d, 5d, 6d, 7d e 8d permite visualizar-se a existência de um acentuado distanciamento entre a última fase vitelogênica (V) e a fase de ovócito hidratado (VI). Tal lacuna é explicada pelo brusco aumento de volume que experimentam os folículos ovarianos nesta etapa de seu desenvolvimento, conforme já observado por Wallace \& Selman (1979), Blaxter \& Hunter (1982), Conover (1985), dentre outros, e utilizado por Kawakami de Resende (1979) e Hunter \& Goldberg (1980) para estimar a fecundidade instantânea, por lote ("batch fecundity"), de Syacium papilosum e Engraulis mordax, respectivamente. No caso das cinco espécies aqui estudadas, comprovou-se que o aumento de volume vinculado à hidratação pré- ovulatória é verdadeiramente significativo, da ordem de seis a oito vezes (Chaves, 1989).

A Tabela 1 carece de determinadas dimensôes ovocitárias, facé à ausência de alguns dados intermediários. Contudo, os valores nela contidos permite que se localize, com bom grau de aproximaçāo, o nível de desenvolvimento em que se encontra um ovócito dotado de um diâmetro qualquer. A conversâo de uma dimensão ovocitária para a fase de desenvolvimento correspondente pode ser feita de imediato. E, se plotada sobre os gráficos das Figuras 47 ou 8 (conforme a espécie), permitirá ainda que se conheça o grau relativo de vitelogênese ou de hidratação em que aquele ovócito se encontra.

Entretanto, é importante salientar aqui que a identificação exata do nível de maturaçāo de um ovário, mesmo conhecendo-se as fases ovocitárias nele presentes, poderá ser levemente deturpada sob a seguinte condição: a de um ovário já ter eliminado parte de seus ovócitos, por desova anterior ao momento da coleta. Neste caso, os folículos pós-ovulatórios, presentes na gônada, não serảo registrados durante as medidas morfométricas, devendo o diagnóstico final estar cercado das devidas precauçōes.

Portanto, consideradas as ressalvas já discutidas, tem-se neste trabalho uma referência inicial para estudos de determinação do grau de maturaçảo ovariana nas cinco espécies estudadas, a partir tāo somente da mensuração dos diâmetros de ovócitos presentes nas gônadas de cada exemplar. 

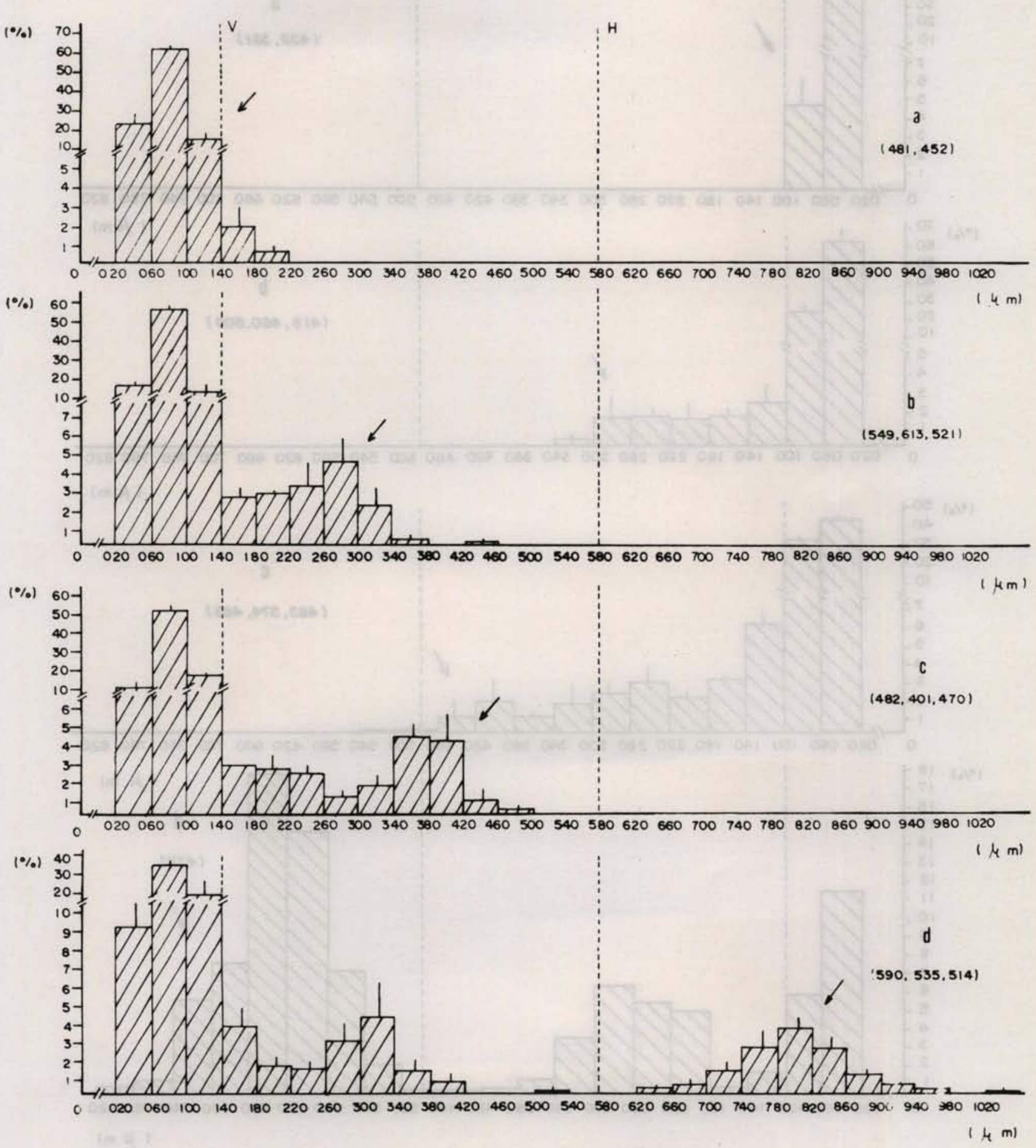

Fig. 4. Distribuição dos diâmetros ovocitários em 11 exemplares deHarengula clupeola. De 'a' a 'd', gônadas cuja maior fase identificada histologicamente foi II, IV, V e VI, respectivamente (setas). As linhas verticais apontam o início estimado das etapas de vitelogênese (V) e hidratação $(\mathrm{H})$. Ovócitos menores que 1 D.O.M. (classe 20-60 $\mu \mathrm{m}$ ) não foram computados. Entre parênteses, o número de células medidas em cada exemplar. Acima de cada coluna, o desvio da média (Sx̄). 
$(\%) \quad 100$

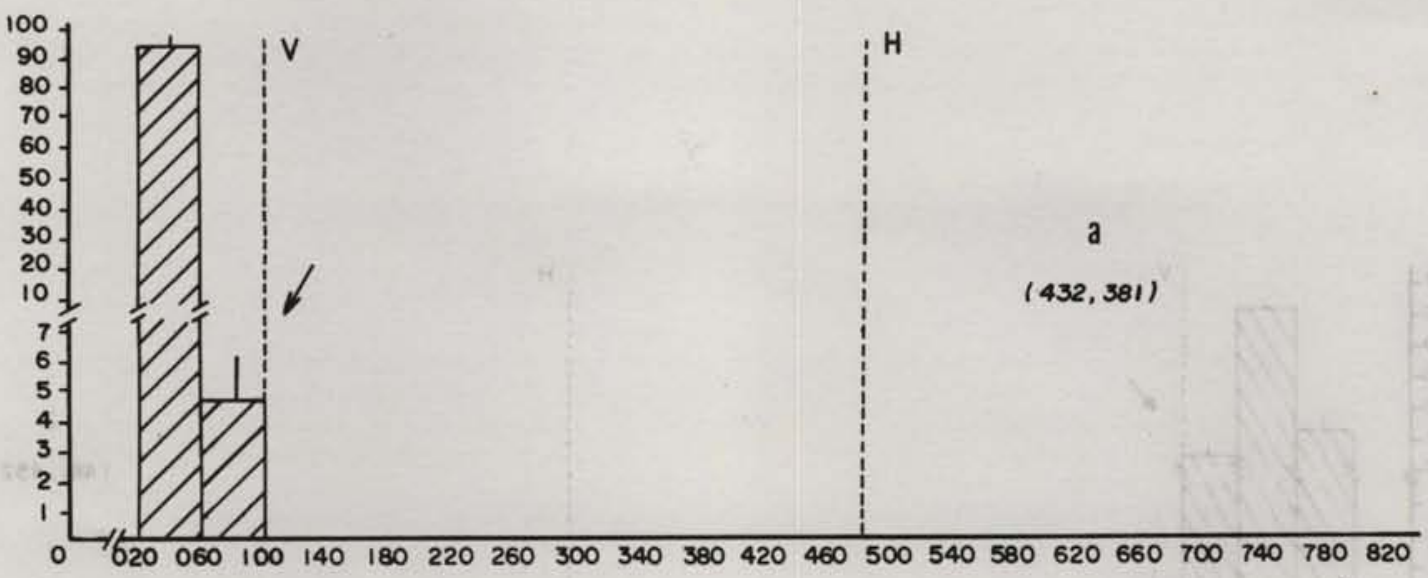

$(\%)$

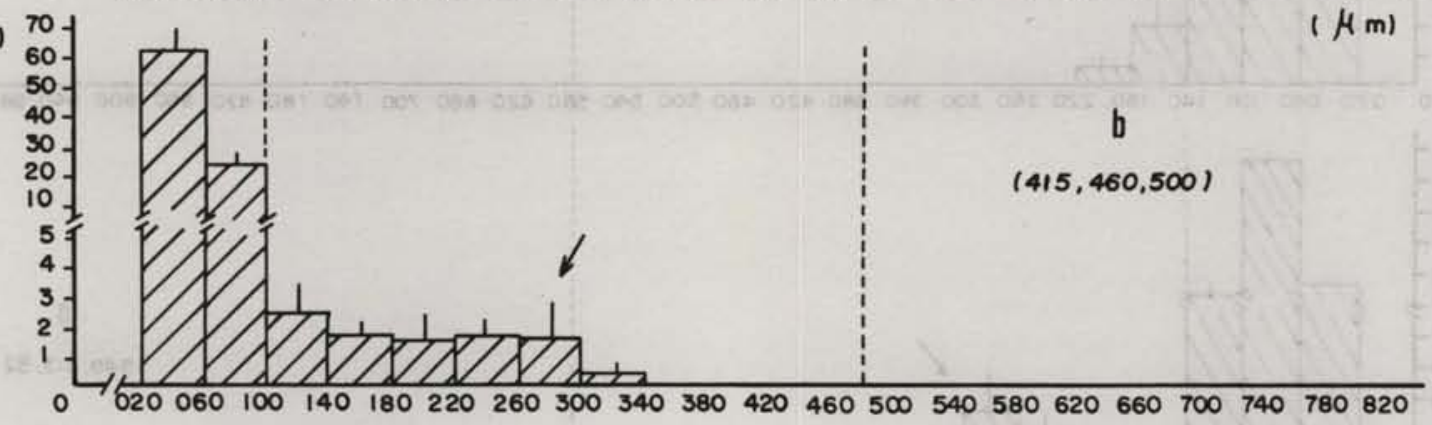

$(\%) 50$

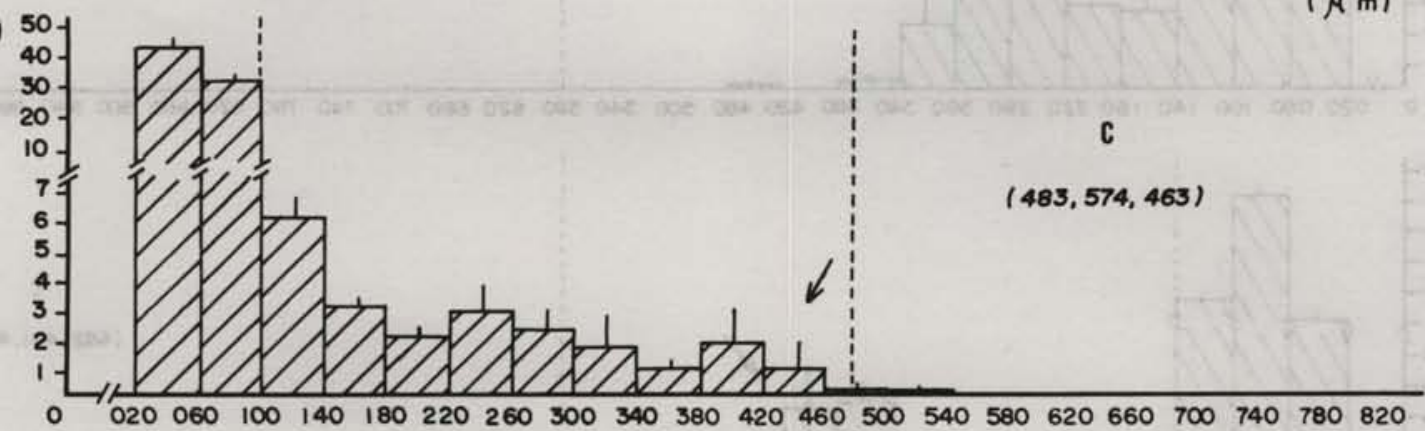

$(\%)$

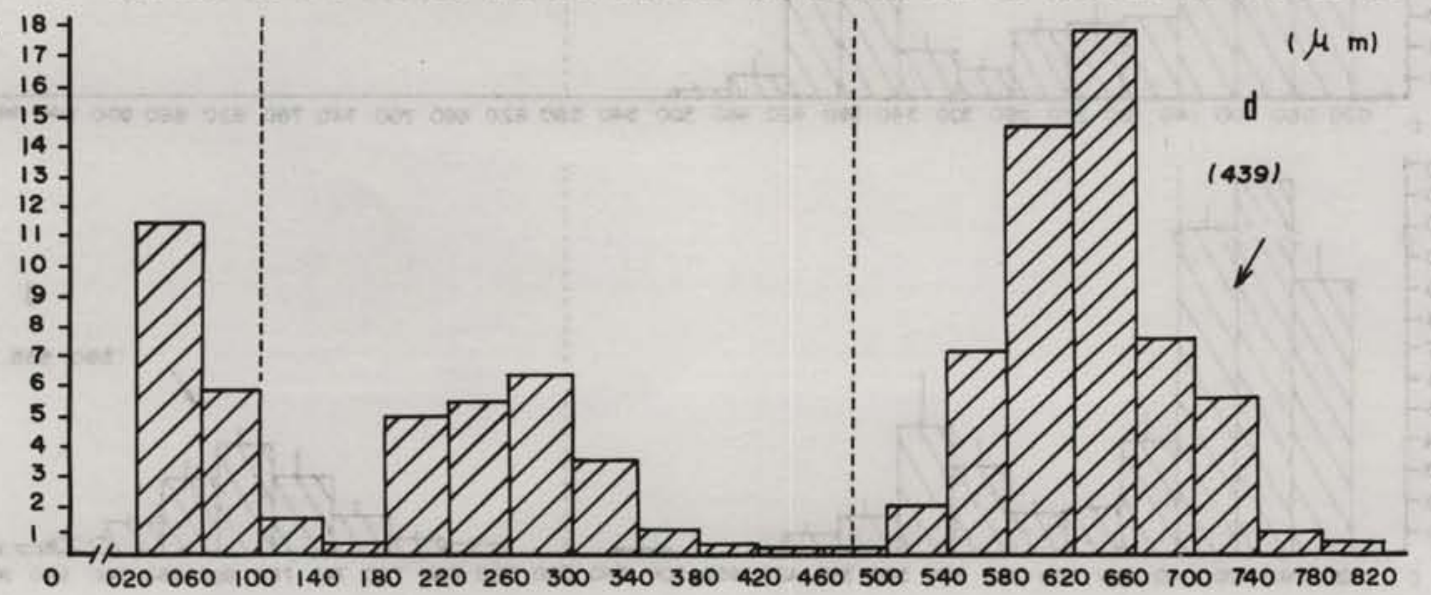

$(\mu \mathrm{m})$

Fig. 5. Distribuição dos diâmetros ovocitários em nove exemplares de Urophycis brasiliensis. De 'a' a 'd', gônadas cuja maior fase identificada histologicamente foi II, III, V e VI, respectivamente (setas). As linhas verticais apontam o início estimado das etapas de vitelogênese $(V)$ e hidratação $(H)$. Ovócitos menores que 1 D.O.M. (classe 20-60 $\mu \mathrm{m}$ ) não foram computados. Entre parênteses, o número de células medidas em cada exemplar. Acima de cada coluna, o desvio da média $(S \bar{x})$. 
$(\%)$

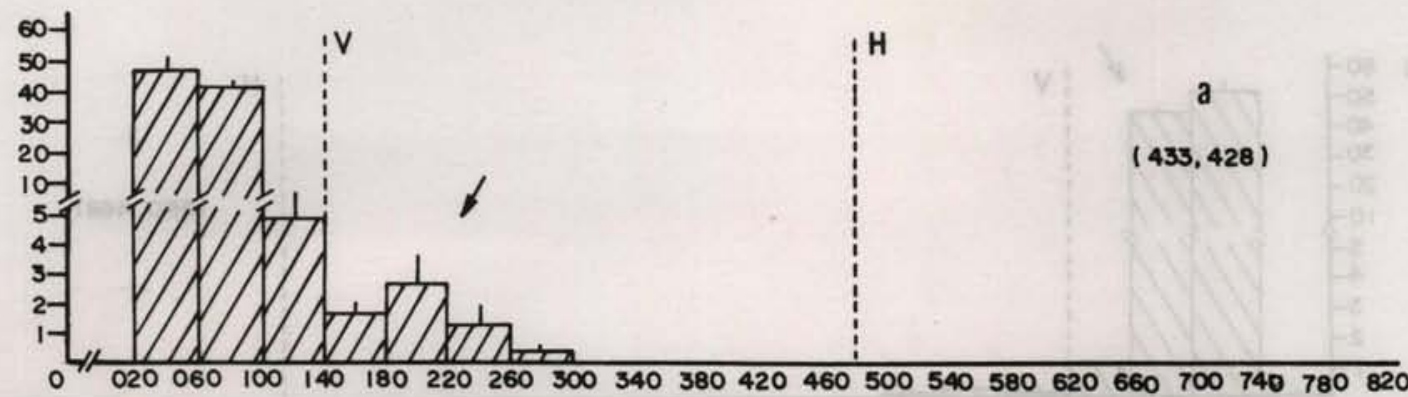

$(\%)$

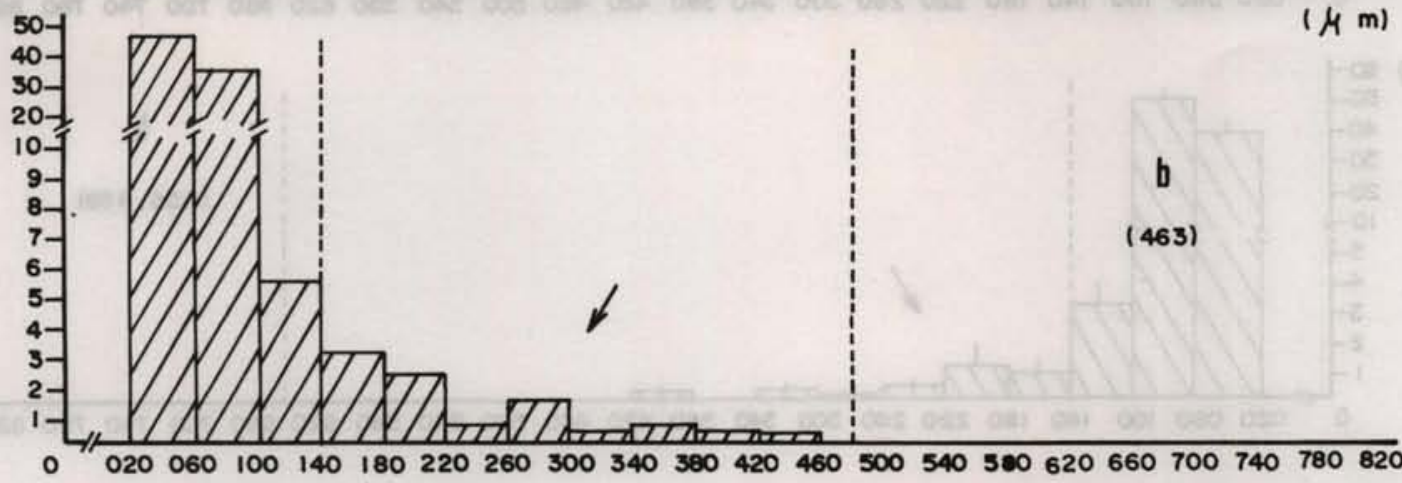

$(\%)$

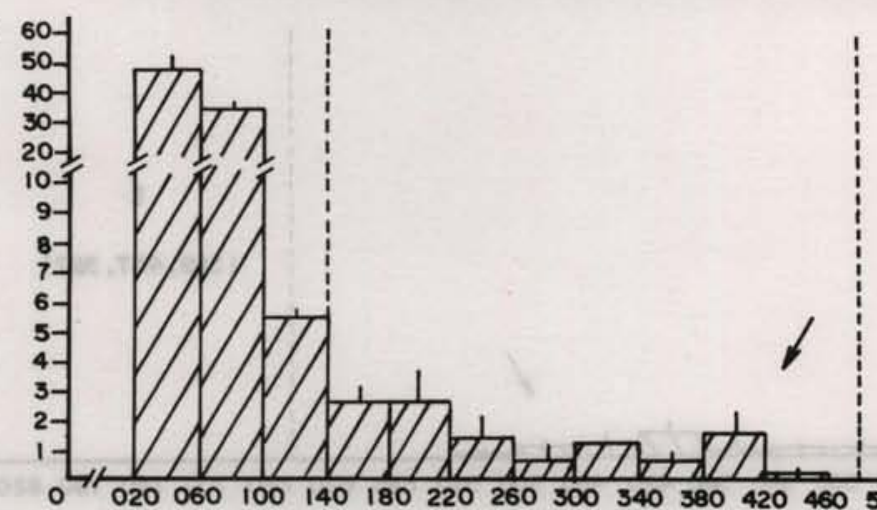

( $\mathrm{A} \mathrm{m)}$

$(\%) 60$

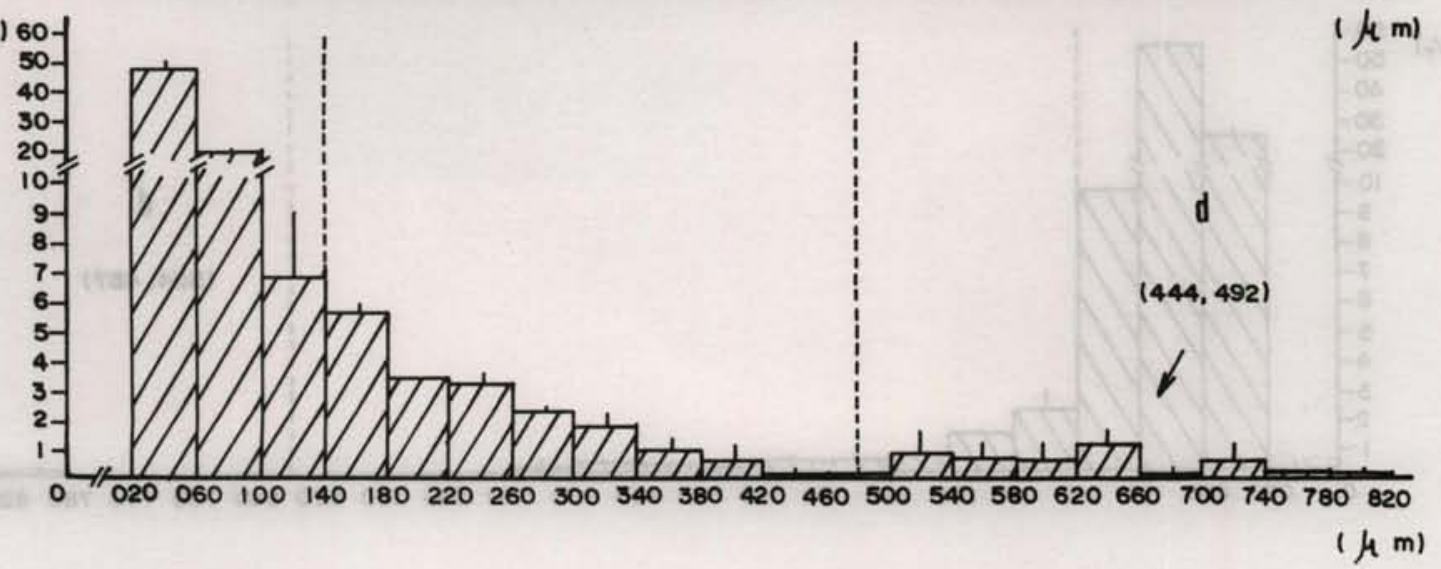

Fig. 6. Distribuição dos diâmetros ovocitários em sete indivíduos de Eucinostomus argenteus. De 'a' a 'd', gônadas cuja maior fase identificada histologicamente foi III, IV, V e VI, respectivamente (setas). As linhas verticais apontam o início estimado das etapas de vitelogênese (V) e hidratação $(\mathrm{H})$. Ovócitos menores que 1 D.O.M. (classe 20-60 $\mu \mathrm{m}$ ) não foram computados. Entre parênteses, o número de células medidas em cada exemplar. Acima de cada coluna, 0 desvio da média (Sx). 

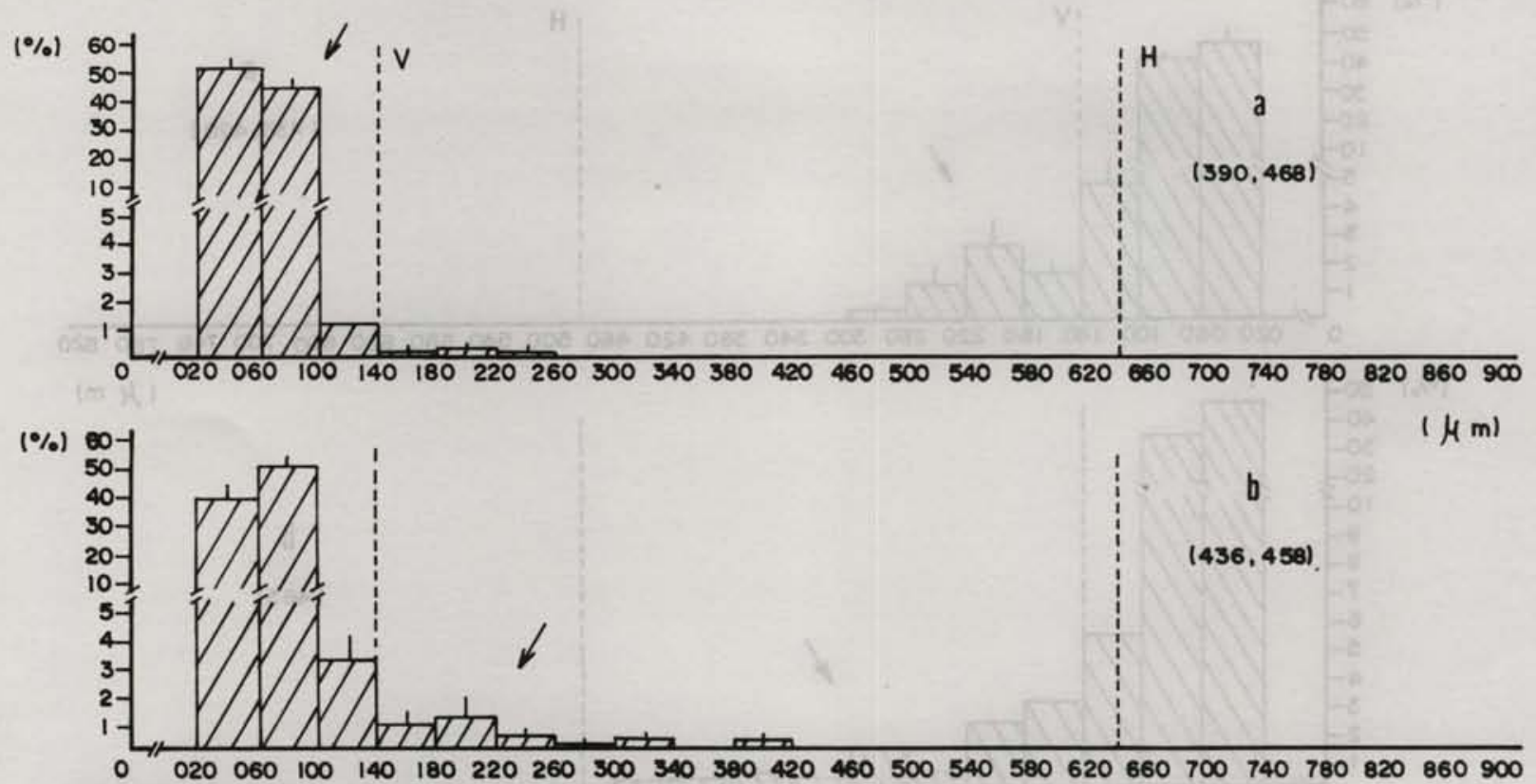

$(\mu \mathrm{m})$

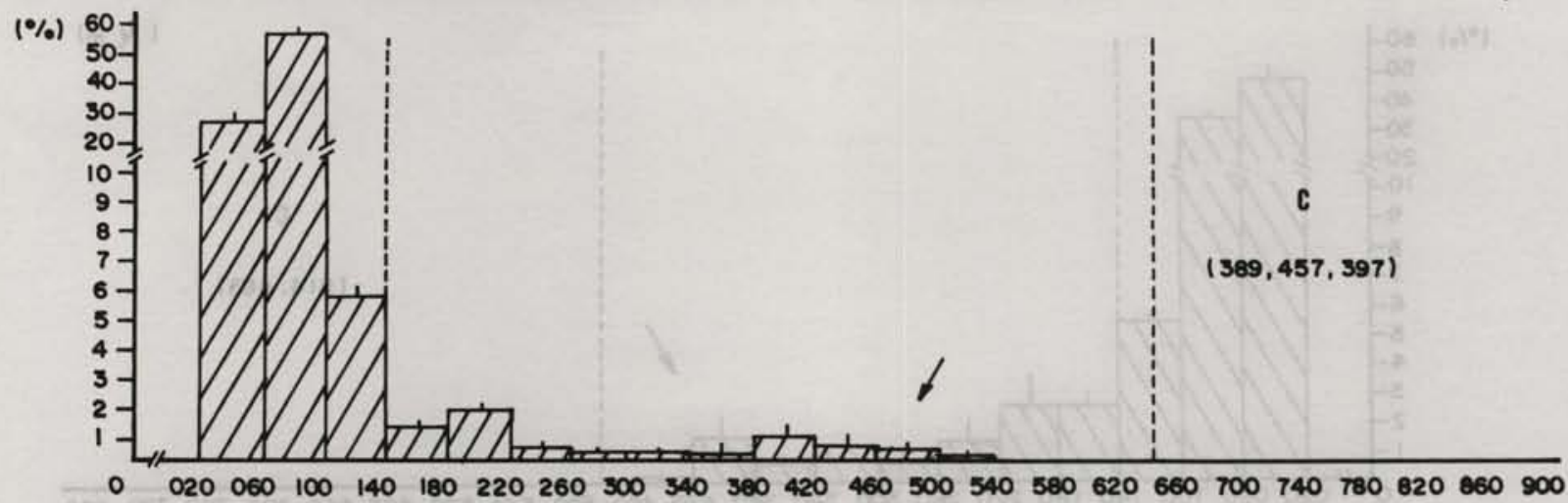

$(\mu \mathrm{m})$

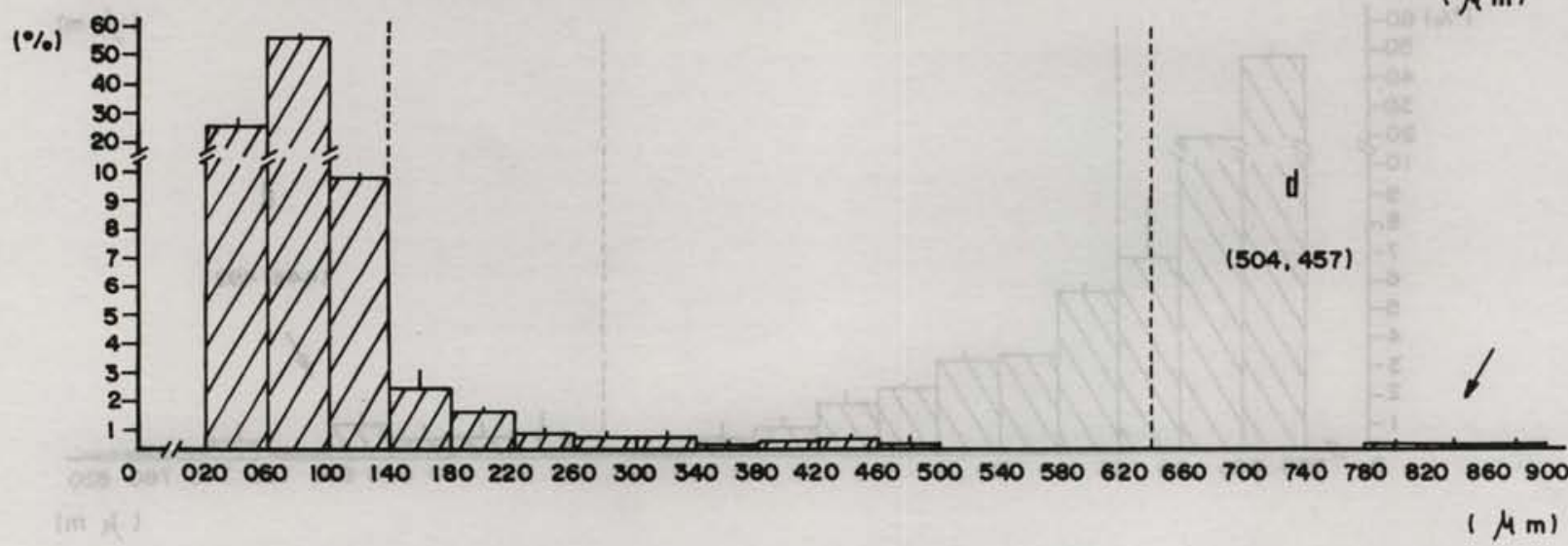

Fig. 7. Distribuição dos diâmetros ovocitários em nove indivíduos de Isopisthus parvipinnis. De 'a' a 'd', gônadas cuja maior fase identificada histologicamente foi II, III, V e VI, respectivamente (setas). As linhas verticais apontam o início estimado das etapas de vitelogênese (V) e hidratação $(H)$. Ovócitos menores que 1 D.O.M. (classe 20-60 $\mu \mathrm{m}$ ) não foram computados. Entre parênteses, o número de células medidas em cada exemplar. Acima de cada coluna, o des-

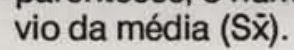




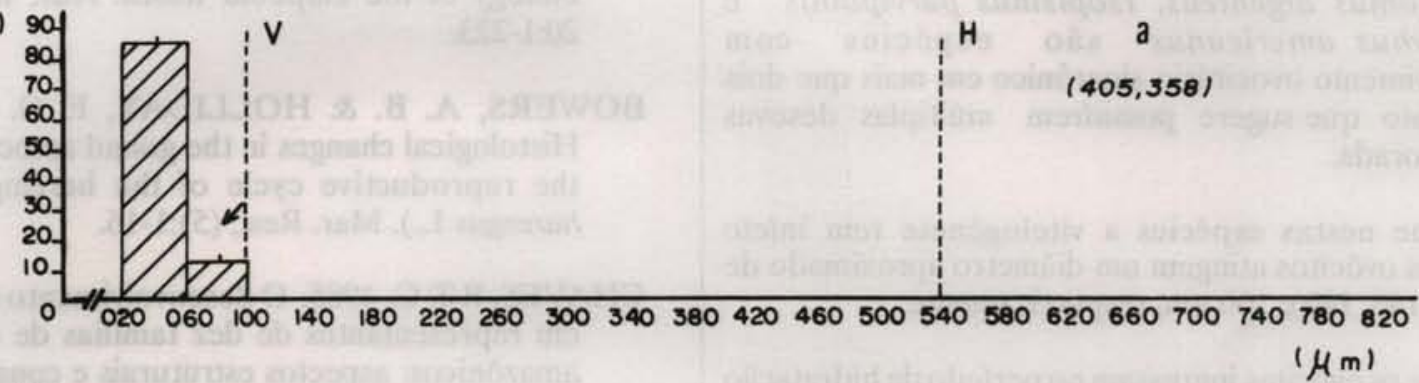

$(\%) 50$

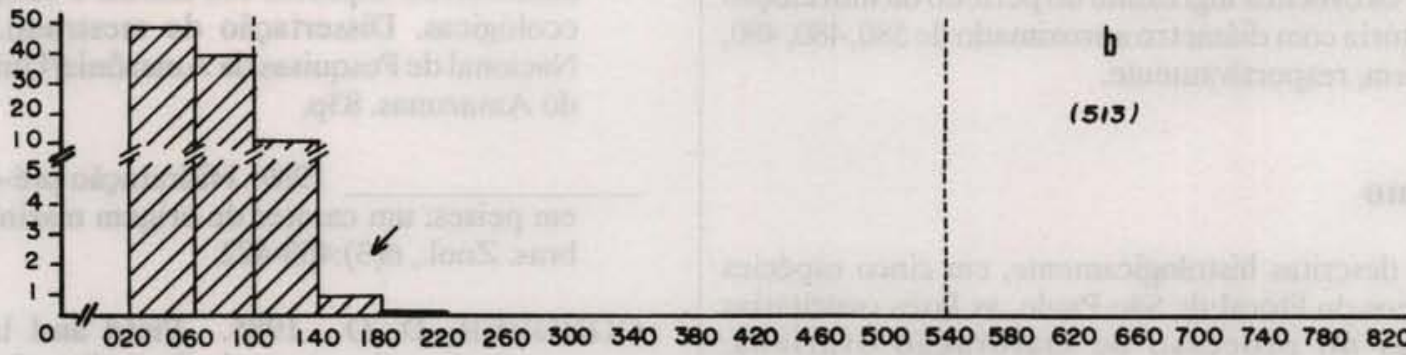

$(\mu \mathrm{m})$

$(\%) \quad 40$

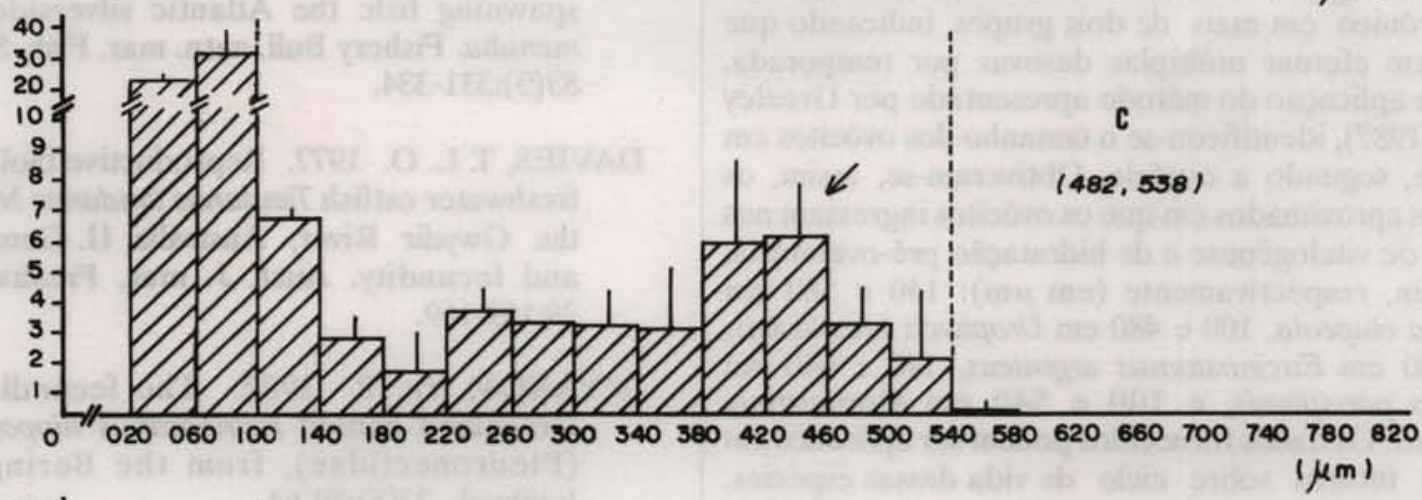

$1 \%$
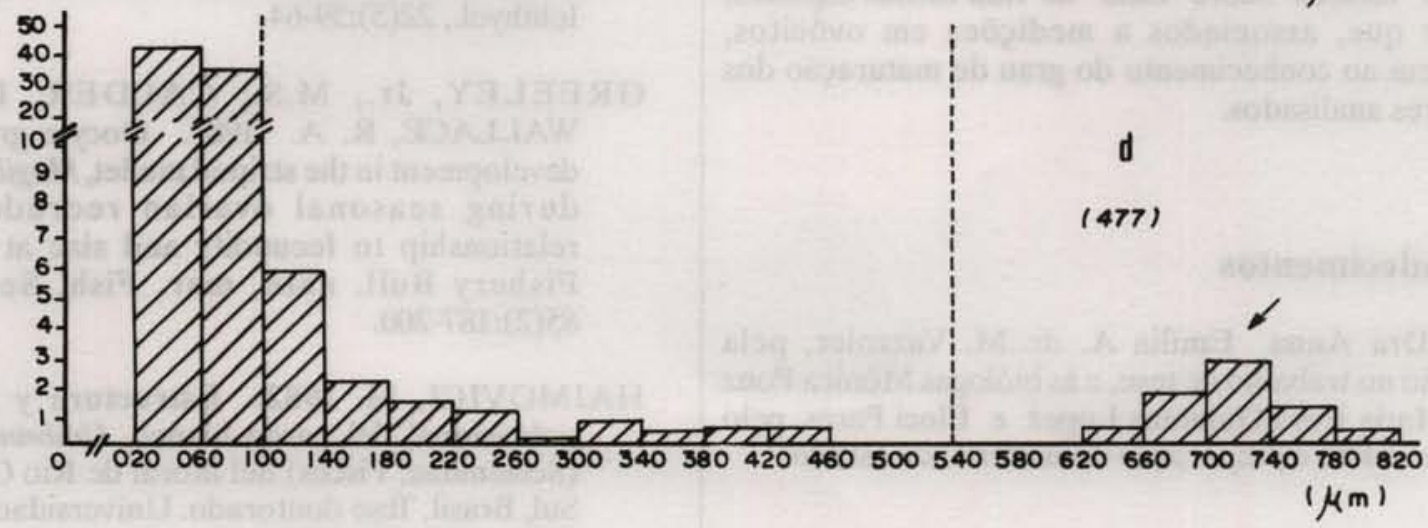

Fig. 8. Distribuição dos diâmetros ovocitários em seis indivíduos de Menticirrhus americanus. De 'a' a 'd', gônadas cuja maior fase identificada histologicamente foi II, III, V e VI, respectivamente (setas). As linhas verticais apontam o início estimado das etapas de vitelogênese (V) e hidratação $(\mathrm{H})$. Ovócitos menores que 1 D.O.M. (classe 20-60 $\mu \mathrm{m}$ ) não foram computados. Entre parênteses, o número de células medidas em cada exemplar. Acima de cada coluna, o desvio da média (Sx̃). 


\section{Síntese dos resultados}

A análise histológica e as mediçōes sobre ovócitos permitiram reconhecer:

$\left.1^{2}\right)$ que Harengula clupeola, Urophycis brasiliensis, Eucinostomus argenteus, Isopisthus parvipinnis e Menticirrhus americanus são espécies com desenvolvimento ovocitário sincrônico em mais que dois grupos, fato que sugere possuírem múltiplas desovas por temporada.

$\left.2^{2}\right)$ que nestas espécies a vitelogênese tem início quando os ovócitos atingem um diâmetro aproximado de $140,100,140,140$ e $100 \mu \mathrm{m}$, respectivamente.

$3^{\circ}$ ) que os ovócitos ingressam no período de hidratação pré- ovulatória com diâmetro aproximado de $580,480,480$, 640 e $540 \mu \mathrm{m}$, respectivamente.

\section{Resumo}

Foram descritas histologicamente, em cinco espécies de teleósteos do litoral de São Paulo, as fases ovocitárias envolvidas no processo de maturação ovariana. Verificou-se que o desenvolvimento dos ovócitos é do tipo sincrônico em mais de dois grupos, indicando que elas devem efetuar múltiplas desovas por temporada. Mediante aplicação do método apresentado por Greeley Jr. et al. (1987), identificou-se o tamanho dos ovócitos em cada fase, segundo a espécie. Obtiveram-se, assim, os diâmetros aproximados em que os ovócitos ingressam nos períodos de vitelogênese e de hidrataçāo pré-ovulatória, que foram, respectivamente (em $\mu \mathrm{m}): 140$ e $580 \mathrm{em}$ Harengula clupeola, 100 e $480 \mathrm{em}$ Urophycis brasiliensis, 140 e 480 em Eucinostomus argenteus, 140 e 640 em Isopisthus parvipinnis, e 100 e 540 em Menticirrhus americanus. Os dados fornecidos podem ser aplicados em trabalhos futuros sobre ciclo de vida dessas espécies, uma vez que, associados a mediçōes em ovócitos, contribuem ao conhecimento do grau de maturaçāo dos exemplares analisados.

\section{Agradecimentos}

À Dra Anna Emília A. de M. Vazzoler, pela orientaçāo no trabalho de tese, e às biólogas Mônica Ponz Louro, Maria Rosa Quintans Lopez e Eloci Peres, pelo auxilio na coleta e preparaçāo do material de estudo.

\section{Referências bibliográficas}

ALVITRES CASTILLO, V. R. 1986. Estudo sobre a biologia e ciclo de vida de Menticirrhus americanus (Linnaeus, 1758) (Ubatuba 2330'S - Cananéia $25^{\circ} 05^{\prime}$ 'S). Dissertaçāo de mestrado. Universidade de Sāo Paulo, Instituto Oceanográfico. 150p.
BEHMER, O. A.; TOLOSA, E. M. \& FREITAS-NETO, A. G. de. 1976. Manual de técnicas para histologia normal e patológica. São Paulo, EDART/EDUSP. 256p.

BLAXTER, J. H. S. \& HUNTER, J. R. 1982. The biology of the clupeoid fishes. Adv. mar. Biol., 20:1-223.

BOWERS, A. B. \& HOLLIDAY, F. G. T. 1961. Histological changes in the gonad associated with the reproductive cycle of the herring (Clupea harengus L.). Mar. Res., (5):1-16.

CHAVES, P. T. C. 1985. O desenvolvimento ovocitário em representantes de dez famílias de teleósteos amazônicos: aspectos estruturais e consideraçōes ecológicas. Dissertação de mestrado. Instituto Nacional de Pesquisas da Amazônia/Universidade do Amazonas. 83p.

1989. Hidratação pré-ovulatória em peixes: um caráter de origem marinha? Revta bras. Zool., 6(3):463-472.

CONOVER, D. O. 1985. Field and laboratory assessment of patterns in fecundity of a multiple spawning fish: the Atlantic silverside Menidia menidia. Fishery Bull. natn. mar. Fish. Serv. U.S., 83(3):331-334.

DAVIES, T. L. O. 1977. Reproductive biology of the freshwater catfish Tandanus tandanus Mitchell, in the Gwydir River, Australia. II. Gonadal cycle and fecundity. Aust. J. mar. Freshwat. Res., 28:159-169.

D'YAKOV, Yu. P. 1982. The fecundity of the Greenland halibut Reinhardtius hippoglossoides (Pleuronectidae), from the Bering Sea. J. Ichthyol., 22(5):59-64.

GREELEY, Jr., M.S.; CALDER, D. R. \& WALLACE, R. A. 1987. Oocyte growth and development in the striped mullet, Mugil cephalus, during seasonal ovarian recrudescence: relationship to fecundity and size at maturity. Fishery Bull. natn. mar. Fish. Serv. U.S., $85(2): 187-200$.

HAIMOVICI, M. 1982. Estructura y dinámica poblacional del pargo blanco, Umbrina canosai (Sciaenidae, Pisces) del litoral de Rio Grande do Sul, Brasil. Tese doutorado. Universidad Nacional de Buenos Aires. 274p.

HISLOP, J. R. G. 1984. A comparison on the reproductive tactics and strategies of cod, haddock, whiting and Norway pout in the North Sea. In: Poots, G. W. \& Wootton, R. J., eds Fish reproduction: tactics and strategies. London, Academic Press. p.311-330. 
HUNTER, J. R. \& GOLDBERG, S. R. 1980. Spawing incidence and batch fecundity in northern anchovy, Engraulis mordax. Fishery Bull. natn. mar. Fish. Serv. U.S., 78(3):641-652.

ISAAC-NAHUM, V. J. 1981. Biologia reprodutiva de Micropogonias furnieri (Desmarest, 1823) (Teleostei, Sciaenidae). Dissertaçāo de mestrado. Universidade de São Paulo, Instituto Oceanográfico. 157 p.

; VAZZOLER, A. E. A. de M. \& ZANETI-PRADO, E. M. 1983. Estudos sobre estrutura, ciclo de vida e comportamento de Sardinella brasiliensis (Steidachner, 1879) na área entre $22^{\circ} \mathrm{S}$ e $28^{\circ} \mathrm{S}$, Brasil. 3. Morfologia e histologia de ovários e escala de maturidade: Bolm Inst. oceanogr., S Paulo, 32(1):1-16.
KAWAKAMI DE RESENDE, E. 1979. Estudo da distribuiçāo, estrutura, biologia e bionomia de Syacium papilosum (Linnaeus, 1758) na plataforma continental brasileira entre Cabo Frio $\left(23^{\circ}\right)$ e Torres $\left(29^{\circ} 21^{\prime} S\right)$. Tese de doutorado. Universidade de São Paulo, Instituto Oceanográfico. 198p.

VAZZOLER, A. E. A. de M. 1981. Manual de métodos para estudos biológicos em populaçōes de peixes. Reprodução e crescimento. Brasilia, CNPq. 106p.

WALLACE, R. A. \& SELMAN, K. 1979. Cellular and dynamic aspects of oocyte growth in teleosts. In: SYMPOSIUM ON DEVELOPMENT BIOLOGY OF FISHES. Annual Meeting of the American Society of Zoology. p.325-339.

(Rebebido em 16-03-89; aceito em 19-10-89) 